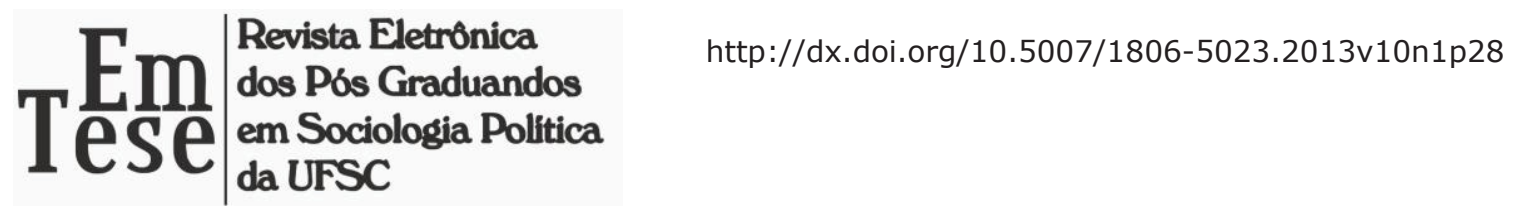

\title{
TEORIA DA ESCOLHA RACIONAL: A EVIDENCIAÇÃO DO HOMO ECONOMICUS?
}

Fernando Scheeffer*

\section{INTRODUÇÃO}

Tanto na Ciência Política como na Sociologia está na pauta da discussão recente o(s) fator(es) que explica a ação coletiva, esta compreendida como a busca de inserção em grupos para o alcance de objetivo(s) individual ou coletivo. O trabalho em conjunto possibilita o alcance de metas que individualmente seriam pouco prováveis de serem atingidas. Mas que metas são essas? O que explica a participação em ações coletivas? O artigo em questão busca enfatizar a abordagem econômica que nos dias de hoje é chamada de "teoria da escolha racional".

Como bem coloca Baert (1997), tem-se a emergência da teoria da escolha racional em tempos recentes e esta é surpreendente e revolucionária, principalmente por defender a emergência do homem econômico. É empregada de forma sofisticada para compreender diversos aspectos da vida social.

Diante disso, o presente trabalho não pretende em hipótese nenhuma esgotar o assunto, mas sim comparar a teoria da escolha racional que enfatiza fatores micro e individuais à perspectiva sociológica que ressalta os determinantes do tipo macro. Feito isso é apresentada e confrontada a abordagem psicossociológica atenta ao nível intermediário. A relação entre comportamento individual e contextos específicos fica clara no conceito de identidade coletiva proposto por Alberto Melucci. Outra intenção é apresentar e analisar criticamente o conceito de racionalidade, alicerce para a teoria da escolha racional.

\footnotetext{
* Mestre em Gestão de Políticas Públicas (UNIVALI) e doutorando em Sociologia Política (UFSC). Contato: fenando@terra.com.br
} 
Se a teoria da escolha racional, nascida nos Estados Unidos, passa a ganhar força nas Ciências Sociais recentemente, sobretudo pela defesa do seu poder explicativo e grau de previsibilidade, esforço interessante é o de testar o quanto que este enfoque cumpre o prometido, dar conta do que leva as pessoas a se inserir em grupos e agir de forma coletiva. Esta questão toma conta do debate contemporâneo através da pretensão de poder ser respondida em sua completude por diferentes teorias e/ou autores. Trazer à tona este debate parece ser de grande valia com o intuito de elencar e relacionar as diversas leituras em relação ao fenômeno.

\section{A TEORIA DA ESCOLHA RACIONAL}

Segundo Ward (2002), a teoria da escolha racional surge entre as décadas de 1950 e 1960 nos Estados Unidos buscando analisar o comportamento dos indivíduos a partir de métodos empíricos. A escolha racional parte do pressuposto básico que os indivíduos são autointeressados. Para o autor esta abordagem tem um alto poder de alcance para explicar o que leva indivíduos a tomarem determinadas ações.

Podem ser considerados os nomes mais importantes desta abordagem Anthony Downs e Mancur Olson dado o pioneirismo de suas premissas neste campo de análise. "Uma teoria econômica da democracia", de Anthony Downs, é publicado em 1957, ao passo que "A lógica da ação coletiva" de Mancur Olson surge um pouco depois, em $1965^{1}$

Downs (1999) começa expondo sua teoria ressaltando algumas características das análises econômicas, sobretudo para enfatizar a aplicação dessas premissas para a compreensão da participação política. Embora a participação política não seja o foco principal do presente trabalho, Downs lança os alicerces fundamentais da teoria da

\footnotetext{
${ }^{1}$ Além de Downs e Olson, Baert (1997) cita como exemplos de aplicação da teoria da escolha racional os trabalhos de Gary Becker (1976) intitulado "Economic approach to human behavior" e "Foundations of social theory" de James Coleman (1990). O primeiro busca ressaltar a aplicabilidade do enfoque econômico a uma grande variedade de fenômenos, enquanto o segundo apresenta uma contribuição à teoria social de uma perspectiva da teoria da escolha racional.
} 
escolha racional, principalmente na ênfase dada ao conceito de racionalidade. Deixa claro dois importantes momentos, sendo um deles a descoberta de quais objetivos aquele que toma a decisão está perseguindo e, o outro, a análise de quais os meios são mais razoáveis para atingi-los. O termo racional refere-se a esse segundo momento, os meios, no qual a concepção de um "homem racional" refere-se àquele que se move em direção às metas estabelecidas despendendo o mínimo de recursos possíveis. $\mathrm{O}$ pressuposto básico é de que um homem racional tenha um desempenho superior a um homem irracional, visto que tende a ser mais eficiente e onde o elemento sorte tende a ficar em segundo plano. $^{2}$

Downs (1999) busca compreender o comportamento eleitoral e a competição partidária. Segundo ele o "motor" dos partidos é o desejo de votos e todo governo busca prioritariamente maximizar o apoio político. Os membros são motivados pela renda, prestígio e poder advindos do cargo ocupado. Em última instância, o principal objetivo de qualquer partido é ganhar as eleições e suas ações serão no sentido de buscar maximizar votos. Estando no governo, a melhor estratégia a ser adotada é optar por escolhas apoiadas pela maioria dos eleitores. Neste caso, entende-se por ação racional aquela eficientemente planejada para chegar aos fins econômicos ou políticos planejados.

$\mathrm{O}$ ato de votar pode ser compreendido pela mesma lógica. O cidadão racional toma a sua decisão levando em conta ganhos e perdas. Quando o ato de votar não tem custo, por exemplo, não faz sentido abster-se. Quando gera custos altos, a abstenção pode ser racional mesmo para aqueles com preferências partidárias claras. Escolhendo votar, em termos gerais, o retorno que o cidadão recebe ao votar "depende (1) dos benefícios que obtém da democracia, (2) de quanto ele quer que um partido específico vença, (3) de quão próxima ele acredita estar a eleição, e (4) de quantos outros cidadãos

\footnotetext{
${ }^{2}$ Downs deixa claro que seu estudo é voltado à racionalidade econômica e política. Embora traga de forma superficial elementos da Psicologia e esta tenha relação próxima tanto com a Economia quanto com a Ciência Política, enfatiza que este não é o foco primordial da sua análise.
} 
ele crê que irão votar" (DOWNS, 1999, p. 293). Essas várias variáveis, em relação, permitem ter uma noção dos retornos possíveis.

Em síntese, Downs (1999) desenvolve duas hipóteses principais. A primeira, a de que a atuação dos partidos está diretamente relacionada à tentativa de maximizar votos; e a segunda, a de que cidadãos se comportam racionalmente em se tratando de política. Segundo ele estas proposições podem ser constatadas empiricamente.

Já Olson (1999), analisando instituições norte-americanas, ${ }^{3}$ busca analisar alguns comportamentos coletivos. Se volta a grandes organizações, e semelhantemente a Downs, defende uma teoria eminentemente econômica. Ele questiona a crença bastante defendida de que grupos de indivíduos sempre agirão para promover os interesses comuns ou grupais. Esta não é uma derivação lógica da premissa do comportamento racional e voltado à satisfação dos próprios interesses. Os grupos não agem em interesse próprio só porque os indivíduos assim o fazem. Além de incompatível, segundo ele, é incoerente esta proposição. Grupos compostos por indivíduos altruístas ou irracionais podem agir em prol de interesses comuns ou grupais, embora, segundo o autor, estes casos são exceção e não a regra. ${ }^{4}$

Sendo que muitas das ações realizadas por um grupo de indivíduos se dá por meio de uma organização, Olson (1999) se volta ao que ele chama de teoria dos grupos sociais e das organizações. Esta abordagem se dá por uma ótica econômica ao prever que em praticamente todas as organizações vê-se uma promoção dos interesses de seus membros. $^{5}$ No seu estudo em particular deixa claro que espera-se que os sindicatos

\footnotetext{
${ }^{3}$ Olson se atém à análise do sindicato e do Estado, sobretudo no que tange à liberdade econômica diante do papel que desempenham.

${ }^{4}$ Em se tratando de grupos pequenos o quadro se complexifica e a lógica é outra. Para Olson pode haver ações em prol dos objetivos comuns dos indivíduos do grupo embora normalmente haja uma tendência a se ter uma dominação do "grande" pelo "pequeno" na divisão de tarefas e custos para se chegar ao objetivo comum.

${ }^{5}$ De acordo com Olson a afirmativa de que as organizações existem para promover os interesses dos seus membros é óbvia e não é de domínio exclusivo da teoria econômica. Esta noção é encontrada já em Aristóteles.
} 
lutem por salários mais altos e melhores condições de trabalho para seus afiliados, assim como o Estado promova os interesses dos cidadãos. Cita ainda as organizações rurais, os cartéis e companhias. Todas estas organizações, segundo o autor, devem privilegiar a promoção dos interesses comuns. Interesses essencialmente individuais e pessoais podem ser defendidos de forma eficiente, embora por ações individuais independentes. Não parece fazer sentido criar uma organização quando uma ação individual e independente tende a servir aos interesses do indivíduo tão bem e, na maioria das vezes, melhor do que uma organização.

A crença de que as organizações existem basicamente para possibilitar o alcance de objetivos comuns de grupos e de indivíduos é algo bastante presente em boa parte da literatura sobre organizações. Algo de certa forma negligenciado é a percepção de que além dos interesses comuns, também se fazem presentes interesses puramente individuais e bastante discrepantes dos interesses dos demais membros do mesmo grupo ou organização. A discrepância pode se tornar uma incompatibilidade na medida em que muitos objetivos individuais só podem ser alcançados em função do não cumprimento dos objetivos dos demais. Esta combinação e relação entre interesses individuais e comuns em uma organização sugere uma analogia com o mercado competitivo (OLSON, 1999).

Para Olson (1999) a racionalidade dos sujeitos é o principal elemento explicativo da ação coletiva. Vale a ressalva de que não se trata exclusivamente da busca por incentivos econômicos, visto que não são os únicos incentivos possíveis. Há uma dimensão psicológica que não pode ser descartada. As pessoas podem ter desejo de prestígio, respeito, dentre outros. Ainda assim são benefícios individuais e nãocoletivos. Trata-se de um levantamento de ônus e bônus em que ao se tratar de benefício coletivo todos os integrantes de um grupo pretendem "consumi-los". Vale ainda a ressalva de que quanto maior o grupo mais difícil o bom provimento do benefício coletivo e, nessa perspectiva, mais sentido faria priorizar os interesses pessoais. A presença de um grupo de pessoas engajadas que fazem parte de organizações que têm causas nitidamente perdidas demonstraria um grau de irracionalidade que a teoria 
proposta por ele não daria conta, o que não acaba sendo um problema por serem situações bastante atípicas.

De forma geral, tanto Downs quanto Olson enfatizam que a promoção de qualquer manifestação grupal não pode ser compreendida se não como uma soma de cálculos racionalmente elaborados, uma relação entre custos e ganhos. Este modelo de análise pode ser classificado como utilitarista ao supor um comportamento autointeressado ao privilegiar a satisfação de objetivos puramente individuais. A ação coletiva, neste sentido, não passa de um somatório de interesses estritamente particulares.

A escolha racional consegue explicar as ações dos indivíduos onde a aplicação da lógica e da matemática a um conjunto de suposições e pressupostos permite que se faça previsões. Esse método apresenta várias vantagens, sendo as mais importantes a necessidade de explicitar claramente as hipóteses e de construir categorias de análise. Corretamente aplicada ela garante ainda proposições oriundas de forma lógica além do que, mesmo em momentos onde a ação é irracional, ela fornece um padrão e propõe variáveis que podem levar a desvios de racionalidade. Em síntese, a escolha racional assume claramente o posicionamento de que indivíduos são autointeressados, mesmo tendo consciência de que o conceito de "interesse pessoal" é poroso. Um exemplo seria refletir sobre o agir de um homem-bomba islâmico. Ele age por interesse pessoal (fazendo isso após sua morte vai direto ao paraíso) ou por uma motivação moral e em nome de uma causa coletiva? (WARD, 2002).

Para Ward (2002) a teoria da escolha racional parte do princípio que os indivíduos têm toda a capacidade racional necessária para escolher o melhor curso da ação, aquele considerado mais viável dentre as alternativas disponíveis. De forma bastante simplificada, o que prevalece é o ideário de que as pessoas não são tolas. Se as pessoas agem de forma casual e acidental, isso é algo incomum e foge da "normalidade". A maioria age de forma racional a partir das alternativas apresentadas e do conjunto de informações a que se tem acesso. 


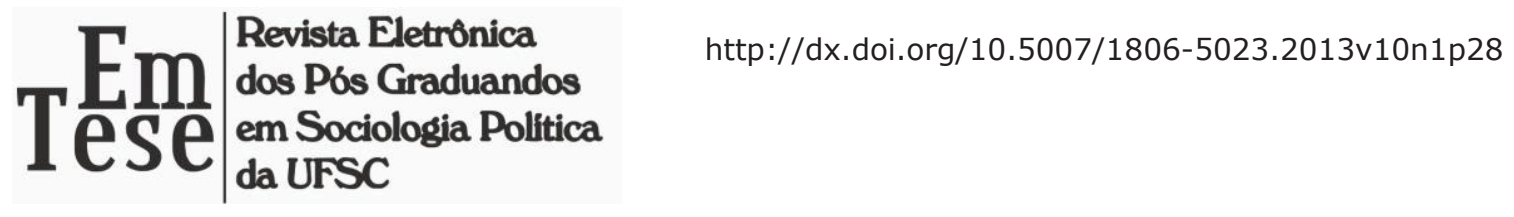

\section{TRANSITANDO POR OUTRAS VIAS EXPLICATIVAS}

Vários teóricos e por perspectivas diferentes questionam a irredutibilidade da vida social à lógica econômica, sobretudo por considerar este um viés reducionista.

Uma das primeiras questões alvo de críticas em se tratando de teoria da escolha racional é o próprio conceito de racionalidade, tipicamente apoiado por teóricos da política. De forma bastante objetiva é possível declarar que "[...] um ato racional é um ato que foi escolhido porque está entre os melhores atos disponíveis para o agente, dadas as suas crenças e os seus desejos" (FEREJOHN; PASQUINO, 2001, p. 7). Dito de outra forma, a interpretação psicológica tradicional desta questão fundamental é de que teríamos estados mentais (crenças e desejos) e escolheríamos as melhores ações que estejam de acordo com eles. Os desejos seriam anteriores às crenças e às ações e estariam relacionados a necessidades humanas básicas (comida, sexo, segurança), como também à posição social ou questões morais.

Analisando criticamente a teoria da escolha racional uma das principais controvérsias se dá na imprecisão do uso do conceito de racionalidade. Converse, citado por Castro (1992), afirma que se entendermos o comportamento racional como aquele que busca maximizar as utilidades esperadas ou percebidas, qualquer comportamento parece se enquadrar como tal, caso contrário o ator teria feito outra escolha. Ao se utilizar um conceito mais restrito de comportamento racional, aquele entendido como um comportamento informado pode-se incorrer em uma contradição: considerando-se o custo da aquisição de informações, pode-se atribuir racionalidade à escolha não informada.

O que está em cena é a racionalidade conferida à ação social. Ao agir e interagir os indivíduos dispõem de planos coerentes e fazem de tudo para maximizar a satisfação de suas preferências e minimizar os custos envolvidos. Esta racionalidade pressupõe um indivíduo capaz de estabelecer uma espécie de ranqueamento das alternativas que estão à disposição. Entretanto, para alguém ser considerado racional, este deve ter a 
capacidade de agrupar informação suficiente para fundamentar suas convicções. A obtenção exagerada de informações pode, nesse caso, ser um sinal de irracionalidade. A análise minuciosa de possíveis estratégias quando um exército está prestes a ser atacado é um exemplo dessa postura que pode trazer consequências desastrosas (BAERT, 1997).

Ferejohn e Pasquino (2001), ao discutirem o conceito de racionalidade em teoria política, expõem que para alguns teóricos a razão é uma capacidade humana e, dessa forma, ser inteiramente humano é ser inteiramente racional. Mesmo assim, a ação racional completa seria uma conquista alcançável apenas por alguns visto que uma parcela significativa das pessoas teria esta capacidade menos desenvolvida e, como consequência, menores graus de racionalidade poderiam ser alcançados ${ }^{6}$.

Outra questão importante relacionada à noção de racionalidade citada por Baert (1997) é a contestável afirmação de que as pessoas agem racionalmente e isso pode ser confirmado empiricamente. Algumas questões alvo de críticas são: quem define o que é racional? Mesmo havendo um cálculo estritamente consciente dos indivíduos, quem determina o "peso" dado pelo indivíduo aos fatores "X" e "Y" que colocados na balança irão determinar ser prudente ou não participar? Outra dimensão importante é: qual a validade de pesquisas que atribuem racionalidade ex post facto, ou seja, que buscam elementos para justificar racionalidade depois dos comportamentos acontecerem? Mesmo parecendo irracionais não parece ser difícil buscar argumentos para considerar qualquer ação como racional. Um último exemplo de pressuposição enganosa é a de que existe um único modo racional de agir, livre de qualquer condicionamento cultural, ou seja, como se o contexto cultural não afetasse direta ou indiretamente qualquer interpretação fundada pelo princípio da razão. Não seria mais interessante pensarmos em uma "auto-reflexão de segunda ordem"? Estas e outras questões colocam em cheque muitas das bases do que alicerça a teoria da escolha racional: a noção de racionalidade.

Castro (1992) a partir da constatação de que a teoria da escolha racional é insuficiente enquanto modelo explicativo se pergunta: Quais são as perspectivas teóricas

\footnotetext{
6 Chama-se de capacidade racional mínima ou racionalidade instrumental aquela universalmente distribuída.
} 
alternativas presentes na produção teórica sobre o tema e em que medida elas se sustentam? Inicia essa discussão buscando apresentar elementos da perspectiva sociológica. Interessada no nível macro sua crença fundamental é a de que a participação dos indivíduos pode ser explicada pelo ambiente socioeconômico e cultural na qual os mesmos estão inseridos, bem como pela inserção em determinados grupos sociais ou categorias demográficas. Em função das influências que recebe e das interações que tem vinculado a grupos específicos, o sujeito sociológico se comportaria. Desta forma, a participação teria uma relação direta e inconciliável com o contexto ou ambiente externo e este determinaria ou explicaria determinado curso de ação ${ }^{7}$.

Enquanto crítica às explicações psicológicas para a formação da ação coletiva, assim como às macroexplicações que defendem que as condições sociais determinam o comportamento dos atores, temos a chamada abordagem psicossociológica que se volta sobretudo ao processo intermediário, ao processo de mediação entre os comportamentos individuais e contextos específicos.

Melucci (2001) é um dos principais defensores desta perspectiva ao defender que a ação coletiva não é produto de crenças e de representações descontextualizadas dos atores, assim como não é resultado natural de momentos históricos específicos. Nesse sentido crítica o enfoque sociológico, sobretudo o marxismo no qual, por exemplo, a mobilização seria explicada como uma emergência espontânea decorrente da condição proletária ou então das contradições do sistema capitalista. Por outro lado, se volta contrariamente à teoria da escolha racional por acreditar que a racionalidade não deriva pura e simplesmente de um intelecto isolado e auto-suficiente. Segundo ele "as crenças dos atores não bastam para dar razão à ação porque não são independentes das relações nas quais os atores estão implicados" (MELUCCI, 2001, p. 32). Se a presença de um interesse em obter um bem coletivo não é suficiente para explicar a ação coletiva, por outro lado a mesma não pode ser interpretada como uma mera soma de comportamentos individuais e do cálculo que cada integrante faz dos custos e benefícios

\footnotetext{
${ }^{7}$ Está vinculada a esta perspectiva a corrente marxista que historicamente ressaltou a importância dos fatores econômicos e a identificação com determinada classe social.
} 
que estão em jogo. Para dar conta desta problemática surge o conceito de identidade coletiva.

Pizzorno (1985), uma das referências de Melucci, questiona algumas das premissas das teorias econômicas da democracia. Segundo ele, a concepção destas teorias chamadas por ele de neo-utilitaristas pecam para explicar comportamentos tão relevantes e complexos como o da participação. Somos tomados por bens tangíveis e simbólicos, e estes terão significados bastante distintos para os diferentes sujeitos interessados. Afinal, o que é útil então? Como proceder para calcular utilidade? Os benefícios são eminentemente subjetivos e relacionados com a identificação com outros indivíduos. Desta forma, não há como descartar a questão de reconhecimento e pertencimento. Por isso, a identidade coletiva é a condição para poderem ser calculados custos e benefícios da ação. A partir dela passam a ser calculáveis os investimentos e retornos da mobilização.

Embora o conceito de identidade coletiva tenha feito parte do debate sociológico recente pelas obras de autores como Touraine e Pizzorno, Melucci (2001) é o que dá maior ênfase ao processo de construção de um ator coletivo sempre em interação, relação e negociação com o ambiente. A presença de uma identidade coletiva, ou de um "nós" com o qual é necessário identificar-se para, a partir daí, ter-se a ação e, mais do que isso, para que possam ser calculados custos e benefícios. Desta forma, a identidade coletiva é a condição para se poder colocar em questão a participação ou nãoparticipação de qualquer tipo de ação social. Desta forma, a motivação para participar não deve e não pode ser concebida como uma variável eminentemente individual. Por mais que não se possa desprezar diferenças psicológicas individuais, estas só podem ser entendidas em interação.

Segundo Alonso (2009), Melucci é o idealizador de uma verdadeira teoria cultural ao analisar a conversão de pessoas comuns em participantes ativos por meio de um processo onde são elementos constituintes racionalidade e emoção. Temos uma apreensão cognitiva dos fins, meios e campos da ação, relação entre os atores envolvidos e investimento emocional que os leva a se reconhecerem enquanto grupo. Estas seriam três dimensões de extrema relevância para a compreensão da ação coletiva. 
A partir do que foi colocado até então, fica evidente que a abordagem adotada por Melucci se coloca em contraposição às teorias psicológicas e sociológicas por se ater ao nível intermediário da análise, ao processo na qual os indivíduos levam em consideração aquilo que os identifica, decidindo a partir disso agir coletivamente ou não. A ação coletiva se constrói a partir das relações sociais que os sujeitos estabelecem e a partir de uma avaliação cognitiva que fazem de um campo de oportunidades e vínculos. As expectativas são construídas e balizadas sempre em conexão com a realidade. $\mathrm{O}$ balanço das potencialidades e limites é produzido durante o próprio curso da ação. Este nível intermediário por longa data foi ignorado.

Cortes (2011) apresenta alguns autores que buscam responder ao chamado "dilema da ação coletiva" proposto por Olson (1999) ao tentar elucidar o que leva os indivíduos a participarem. Diferentemente do autor, são ressaltados aspectos diversos como a ampliação das interações sociais, de capital social, capacidade para participar politicamente, fomento do sentimento de dever cívico, dentre outras questões consideradas extremamente relevantes.

Seguindo a mesma linha de raciocínio, McAdam, Tarroy e Tilly (2009) questionam a ênfase dado ao ativismo individual pela teoria da escolha racional. "Temse a imagem de um outsider isolado e decidindo se vai ou não aderir a uma certa ação coletiva 'oferecida' por algum tipo de empreendedor" (p. 30). Este enfoque peca ao descartar um certo grau de inserção e investimento ontológico dos indivíduos em questões e problemas coletivos. De forma contraditória, por que não pensar que a maioria das pessoas participe da ação coletiva dada a filiação em comunidades que lhe instrumentaliza de significados e identidades essenciais para sua vida e bem-estar? Visto desta forma não há nenhum cálculo consciente de ganhos e perdas por parte do indivíduo.

A ideia de autointeresse desabona qualquer iniciativa relacionada ao altruísmo, como se o senso grupal e o bem comum não pudessem ser motivadores para a ação coletiva. Se a resposta a essa colocação é a de que este pode ser um comportamento racional visto que se trata de uma satisfação de algo considerado importante para a 
pessoa, que trará um bem-estar psicológico, não será essa concepção de racionalidade muito abrangente? Será algum comportamento não-racional?

Segundo Scheeffer (2012), falar de relações sociais é falar de pessoas e, portanto, falar de relacionamentos nos mais diversos espaços relacionais: família comunidade, associações, instituições, todos eles sempre tendo como pano de fundo valores, crenças e ideologias. Compreender quem somos e o que desejamos nos leva ao encontro do "outro". Não há a possibilidade de compreendermos o comportamento humano sem nos atermos ao social.

O fato é que pressupor que o ser humano é naturalmente individualista ou altruísta é desconsiderar uma discussão já ultrapassada na Psicologia, essência versus existência. Não nascemos prontos, com uma essência, e dessa forma o comportamento humano só pode ser entendido a partir das diversas relações sociais estabelecidas ao longo da vida. Como colocam Bock, Furtado e Teixeira (2002, p. 170), "A única aptidão inata no homem é a aptidão para a formação de outras aptidões". Assim, o comportamento humano não se dá a partir de uma relação causa-efeito, pelo contrário, é multicausal e como tal complexo. Qualquer tentativa de regra ou "fórmula" que sirva para todos não passa de uma tentativa grosseira de simplificação.

\section{CONSIDERAÇÕES FINAIS}

Assim como Ward (2002) afirma, parece fazer sentido compreender a teoria da escolha racional enquanto uma parte indispensável da caixa de ferramentas do cientista político e não uma abordagem. Desta forma, acaba sendo irresponsável não levar em consideração a crítica sociológica. O individualismo metodológico, embora traga elementos importantes, concebido de forma isolada não passa de uma explicação reducionista e como tal impraticável. Isso não traz boas razões para se abandonar a suposição de racionalidade dos sujeitos atuantes, embora pareça ser mais adequado falar em ação intencional, mais ou menos egoísta, menos ou mais influenciada por fatores externos, conjuntamente racional e ideológica. 
Berlin (2002) expõe o quão complicado é a tentativa exageradamente entusiástica de aplicar ao contexto geral algo que foi pensado para explicar um setor da vida. Poderíamos pensar de forma diferente o quão limitado é compreender a ação coletiva a partir de uma única abordagem quando vivenciamos um fenômeno multifacetado e multivariado. Segundo o autor parece que vez ou outra retomamos a antiga falácia dos filósofos jônicos que buscavam uma resposta única e definitiva para a pergunta: "De que são feitas as coisas"? Infelizmente tudo não é feito de água, nem de fogo, assim como tudo não pode ser explicado pela escolha racional ou por um viés eminentemente sociológico.

Se é inviável negarmos o "homo economicus" e o poder explicativo da teoria da escolha racional, perspectivas do tipo macro ressaltam o "homo sociologicus", o que parece ser também de bastante valia. Embora tenhamos de ter cuidado ao tratar de um certo ecletismo, pois podemos cair no erro de conciliar teorias inconciliáveis, esse não parece ser o caso em se tratando das possibilidades de compreensão da ação coletiva. Se são válidas as explicações psicológicas, bem como as sociológicas, o grande equívoco talvez esteja em compreender estas instâncias como não inter-relacionadas, a relação entre os níveis micro e macro, ou melhor dizendo, entre os sujeitos e o contexto. Este impasse talvez seja resolvido pelas teorias do tipo psicossociológicas que não desmerecem um ou outro nível da vida social, pelo contrário, se voltam à análise das mediações entre comportamentos individuais e o fenômeno coletivo.

Neste sentido, a escolha de uma perspectiva seja difícil, visto que estamos tratando de um "homo complexus" e onde a relação de causa e efeito não cabe. Estamos falando de sujeitos em relação e tais visões parciais acabam por limitando a compreensão de um fenômeno extremamente diverso. Vale ainda a ressalva de que a necessidade de delimitação de que ação coletiva estamos tratando também é imprescindível para podermos afirmar qual teoria ou abordagem tem maior alcance, o que se demonstra ser possível afirmar apenas a posteriori e não a priori. 


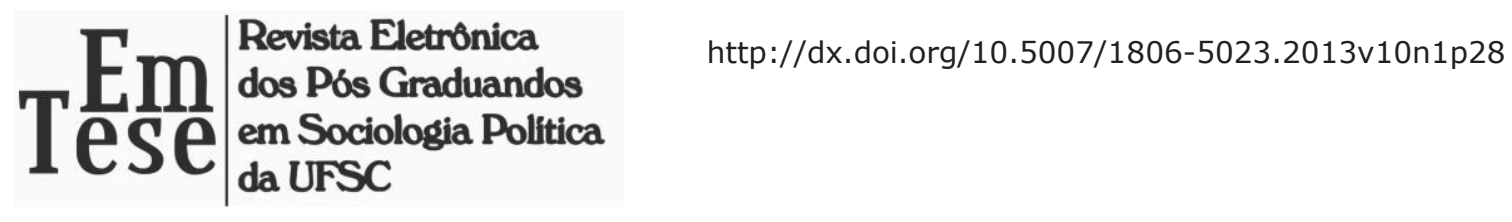

\section{REFERÊNCIAS}

ALONSO, Angela. As teorias dos movimentos sociais: um balanço do debate. Lua Nova, São Paulo, n. 76, p. 49-86, 2009.

BAERT, Patrick. Algumas limitações das explicações da escolha racional na Ciência Política e na Sociologia. Revista Brasileira de Ciências Sociais, São Paulo, v. 12, n. 35, Oct. 1997.Disponível em:

$<$ http://www.scielo.br/scielo.php?script=sci_arttext\&pid=S0102-

69091997000300005\&lng=en\&nrm=iso $>$. Acesso em: 11 mai. 2013.

BERLIN, Isaiah. Ainda existe a teoria política? In: HARDY, H.; HAUSHEER, R. (orgs.). Isaiah Berlin: Estudos sobre a Humanidade. São Paulo: Companhia das Letras, 2002.

BOCK, Ana Mercês Bahia; FURTADO, Odair; TEIXEIRA, Maria de Lourdes Trassi. Psicologias: uma introdução ao estudo de Psicologia. São Paulo: Saraiva, 2002.

CASTRO, Mônica Mata Machado. Sujeito e estrutura no comportamento eleitoral. Revista Brasileira de Ciências Sociais, n. 20, São Paulo, Anpocs, 1992.

CORTES, Soraya Vargas. Instituições participativas e acesso a serviços públicos nos municípios brasileiros. In: PIRES, Roberto Rocha C (Org.). Efetividade das instituições participativas no Brasil: estratégias de avaliação. Brasília: IPEA, 2011.

DOWNS, Anthony. Uma teoria econômica da democracia. São Paulo: EDUSP, 1999.

FEREJOHN, John; PASQUINO, Pasquale. A teoria da escolha racional na ciência política: conceitos de racionalidade em teoria política. Rev. bras. Ci. Soc., São Paulo, v. 16, n. 45, fev. 2001 Disponível em: $<$ http://www.scielo.br/scielo.php?script=sci_arttext\&pid=S010269092001000100001\&lng=pt\&nrm=iso >. Acesso em 18 abr. 2013.

McADAM, Doug; TARROW, Sidney; TILLY, Charles. Para mapear o confronto político. Lua Nova, São Paulo, 76: 11-48, 2009.

MELUCCI, Alberto. A invenção do presente: movimentos sociais nas sociedades complexas. Petrópolis, RJ: Vozes, 2001.

OLSON, Mancur. A lógica da ação coletiva: os benefícios públicos e uma teoria dos grupos sociais. São Paulo: EDUSP, 1999. 
PIZZORNO, Alessandro et al. Los límites de la democracia. Buenos Aires: Santo Domingo, 1985.

SCHEEFFER, Fernando. Psicologia social. Indaial: Uniasselvi, 2012.

WARD, Hugh. Rational choice. In: MARSH, David; STORKER, Gerry. Theory and methods in Political Science. 2. ed. Basingstoke et al.: Palgrave Macmillan, 2002. p. 65-89.

\title{
RESUMO
}

Não há como negar que recentemente a abordagem econômica, ou também conhecida como teoria da escolha racional, ganha corpo na Ciência Política e na Sociologia, sobretudo para explicar a ação coletiva, ou então, o que leva os indivíduos a participarem e agirem enquanto grupo. Diante desse contexto, o presente trabalho pretende expor os principais pressupostos da teoria da escolha racional, para em um segundo momento testá-los com o intuito de saber em que medida este enfoque tem um bom poder explicativo. Para tal é apresentado e questionado o conceito de racionalidade, alicerce fundamental da teoria da escolha racional, e contraposta a mesma ao enfoque sociológico e principalmente à abordagem psicossociológica. De fato, embora tenhamos um homem racional e autointeressado, parece coerente afirmar que esta é uma dentre várias abordagens que se prendem a aspectos diversos para buscar compreender um homem complexo e multifacetado. Neste âmbito o enfoque psicossociológico ganha destaque por conseguir assimilar este entrave e compreendê-lo enquanto ser em relação, ou seja, dando ênfase aos atores coletivos sempre em interação, relação e negociação com o que os rodeia.

PALAVRAS-CHAVE: Ação Coletiva. Teoria da Escolha Racional. Homo Economicus.

\section{RATIONAL CHOICE THEORY: THE DISCLOSURE OF HOMO ECONOMICUS?}

\begin{abstract}
There is no denying that the recent economic approach, or also known as rational choice theory, grows in Political Science and Sociology, especially to explain the collective action, or, what leads individuals to participate and act as a group. In this context, the present work aims to expose the main assumptions of the rational choice theory, and in
\end{abstract}


a second phase, test them in order to know in what extent has this approach a good explanatory power. For this is presented and questioned the concept of rationality, the essential foundation of rational choice theory, and opposed to the same sociological approach and especially the social psychological approach. In fact, although we have a rational and self-interested man, it seems consistent to say that this is one of several approaches that relate to various aspects to seek the understanding of a complex and multifaceted man. In this context the psychosocial approach is highlighted because it assimilates this obstacle and understands it as being in relation, in other words, emphasizing the collective actors always in interaction, relationship and negotiation with their surroundings.

KEYWORDS: Collective Action. Rational Choice Theory. Homo Economicus.

Recebido em: 22 de Julho de 2013

Aceito para publicação em: 15 de Setembro de 2013 